Research Article

\title{
Metaheuristic Approaches Integrated with ANN in Forecasting Daily Emergency Department Visits
}

\author{
Engin Pekel $\left(\mathbb{D},{ }^{1}\right.$ Muhammet Gul $\mathbb{D D}^{2}$ Erkan Celik $\mathbb{D}^{3},{ }^{3}$ and Samuel Yousefi $\mathbb{D}^{4}$ \\ ${ }^{1}$ Department of Industrial Engineering, Hitit University, 19000 Çorum, Turkey \\ ${ }^{2}$ Department of Emergency Aid and Disaster Management, Munzur University, 62000 Tunceli, Turkey \\ ${ }^{3}$ Department of Transportation and Logistics, Istanbul University, 34320 İstanbul, Turkey \\ ${ }^{4}$ Faculty of Industrial Engineering, Urmia University of Technology, Urmia, Iran \\ Correspondence should be addressed to Muhammet Gul; muhammetgul@munzur.edu.tr
}

Received 28 March 2021; Revised 26 April 2021; Accepted 5 November 2021; Published 27 November 2021

Academic Editor: Laurent Dewasme

Copyright ( $\odot 2021$ Engin Pekel et al. This is an open access article distributed under the Creative Commons Attribution License, which permits unrestricted use, distribution, and reproduction in any medium, provided the original work is properly cited.

\begin{abstract}
The overall service quality level of Emergency Departments (EDs) can be improved by accurate forecasting of patient visits. Accordingly, this study aims to evaluate the use of three metaheuristic approaches integrated with Artificial Neural Network (ANN) in forecasting daily ED visits. To do this, five performance measures are used for evaluating the accuracy of the proposed approaches, including Bayesian ANN, Genetic Algorithm-based ANN (GA-ANN), and Particle Swarm Optimization algorithmbased ANN (PSO-ANN). The outputs of this study show that the PSO-ANN model provides the most dominant performance in both the training and testing process. The lowest error is obtained with a mean absolute percentage error (MAPE) of 6.3\%, Mean Absolute Error (MAE) of 42.797, Mean Squared Error (MSE) of 2499.340, Root Mean Square Error (RMSE) of 49.933, and Rsquared $\left(R^{2}\right)$ of 0.824 on the training dataset. The lowest error with an MAPE of 6.0\%, MAE of 40.888, MSE of 2839.998, RMSE of 53.292 , and $R^{2}$ of 0.791 is also obtained on the testing process.
\end{abstract}

\section{Introduction}

Emergency Departments (EDs) are the units that perform very crucial duties within the hospital service system and provide uninterrupted service. Also, these departments are the sole units where the patient traffic and transfer is the most and overcrowding is felt too much [1]. When this is the case, it is vital to improving the provided service quality level by newly adopted methodologies. Improving the service quality means a decreased waiting time, decreased length of stay, and increased ED throughput. These key performance metrics are directly interrelated with the daily patient volume of the EDs. Patient visits at the emergency departments cover 40\%-70\% of all hospital care [2]. The density of patient visits at the EDs on hourly, daily, weekly, monthly, or yearly basis will assist in arranging and allocating human and material resources (number of doctors, nurses, receptionists, medical devices, ED bed, and medicines). Therefore, accurate forecasting of patient visits gains great importance to ED decision makers.
The main aim of forecasting ED patient visits is to inform about the pattern of changes in the density of visits in the future [3]. The forecasting studies regarding ED visits have several dimensions such as time frame, forecasting methodology, the independent variables used in the modeling, and measurement of the model's accuracy $[4,5]$.

The remainder of the study is organized as follows: Section 2 presents both an overview on contemporary real-life case studies of ANN and ED patient visit forecast in the light of four dimensions. Section 3 includes ANN-based solution approaches with their pseudocodes. In section 4, the case study is demonstrated. Section 5 provides analysis results and a deep discussion. The final section presents the conclusion, future recommendations, and limitations of the study.

\section{Literature Review}

2.1. Overview on ED Patient Visit Forecast in the Light of Four Dimensions. ED patient visit forecasting, also called ED 
patient volume forecasting or ED patient admission forecasting, is the problem of forecasting the future patient arrival of an ED. For that purpose, the historical data demonstrated as a time series are gathered in a regular time frame of hourly [6, 7], daily [8-13], weekly [14], monthly [15] and yearly [16] basis. Based on the literature, the vast majority of studies focus daily $[5,17]$. The time frame also has an impact on the accuracy of the forecasting model. The smaller the interval of the time frame, the lower the relative accuracy of the model as compared to the models with a higher interval of the time frame (for example, annual ED patient visit forecasting) [7, 17, 18]. Furthermore, daily patient visits are the mostly dealt topics for the researchers since the forecasts play an important role in scheduling ED medical personnel, which is one of the most considerable problems faced by hospital management.

Another dimension concerns forecasting methodology. In the work of Nas and Koyuncu [19], it is stated that the studies regarding modeling the ED patient visits generally apply two types of methods. While the first one analyzes the correlations between patient visits and several regression variables, such as calendar or climatic variables, the second one predicts future values from the past values considering patient visits follow a time series [19]. These two groups propose regression-based and time series-based models, respectively. Apart from this, there exist machine learningbased models such as Artificial Neural Network (ANN), Support Vector Machine (SVM), and Long Short-Term Memory Network (LSTM) that are applied to ED patient visit forecasting. A similar grouping is mentioned in Yousefi et al.'s [20] study. They distinguish methods used in ED patient visit forecasting under two groups, namely, linear and nonlinear methods. Linear methods include HoltWinters, Multiple Linear Regression (MLR), Exponential Smoothing (ES), Autoregressive Integrated Moving Average (ARIMA), Seasonal Autoregressive Integrated Moving Average (SARIMA), and some other regression-based methods $[18,21-23]$. Nonlinear methods include the adaptive NeuroFuzzy Inference System (ANFIS), ANN, SVM, and LSTM $[20,24-26]$. In addition to these two groups of methods, some hybrid approaches are developed for this problem to benefit from the advantages of the usage of these methods either individually or integrated, improve accuracy, and decrease modeling errors [12, 14, 27]. Regression-based models are incorporated with machine learning-based (e.g., MLR-ANN) and time series-based models (MLR-ARIMA).

One of the most important dimensions of the ED patient visit forecasting studies are regarding the independent variables used in the model. In the literature, the variables include time-related (temporal or calendar), demographic, and climatic variables. In the literature, scholars mostly agree on a result that time-related variables have more impact than weather variables in forecasting ED patient visits [27-29]. Most of the authors deal with temporal variables such as the day of the week, the month of the year, holidays (school or public), the day after the holiday, the day before the holiday, and soccer match day [19]. Climatic variables such as air temperature, humidity, and wind speed are considered secondarily by the scholars [28-30]. Some other variables related to demography, transportation, epidemic, and hospital reputation are also studied [31].

The measurement of the accuracy of the model is also an important dimension in ED patient visit forecasting studies. Different measures, such as Mean Absolute Percentage Error (MAPE), Mean Squared Error (MSE), Mean Absolute Error (MAE), Receiver Operating Characteristic (ROC) curve value, Root Mean Square Error (RMSE), and $R$-squared, are used in the studies to test the accuracy of the models. The accuracy of the developed models is changed with respect to the chosen variables and some specific parameters (e.g., the number of hidden layers, learning rate, and momentum in ANN modeling). By setting up these, the developed models can be performed better. Most studies regarding ED patient visit forecasting prefer MAPE to measure the accuracy. In the Wargon et al.'s [17] review paper, the investigated studies that focus on daily ED visits result in an MAPE value of between $4.2 \%$ and $14.4 \%$. That means an MAPE value which is lower than $10 \%$ or around $10 \%$ indicates good statistical predictability.

2.2. Research Gaps and Contributions of the Study. This study focuses on the dimension of "forecasting methodology" that is mentioned in the second order. We dealt with the applicability of metaheuristics integrated with ANN in ED patient visit forecasting. In this context, three hybridized ANN-based approaches are applied to the data of daily ED visits for the first time in the literature. These approaches are Bayesian ANN, Genetic Algorithm-based ANN (GA-ANN), and Particle Swarm Optimization algorithm-based ANN (PSO-ANN). Although plenty of hybridized approaches are proposed in the literature, the metaheuristic algorithms are not yet incorporated with regression, time series, and machine learning algorithm-based methods, which are appropriate for the nature of this problem. Therefore, this study will remedy the gap in the literature and contributes a lot by the following aspects:

(i) Approaches utilizing metaheuristics algorithms merged with ANN are applied to the daily ED patient visit forecasting problem (a novelty for the methodological viewpoint)

(ii) A comparative outline is produced by making a benchmark analysis between three approaches in terms of a common forecast accuracy measure "MAPE" (a novelty for the methodological viewpoint)

(iii) A case study in a public hospital in Istanbul (Turkey) is carried out to demonstrate the applicability of the approaches (a novelty for the application viewpoint)

\section{ANN-Based Solution Approaches}

3.1. Bayesian ANN. ANN provides solutions to problems in many different areas from natural science to engineering [32-34], social science [35, 36], and health science [37]. It has been developed for further improvement of targeted 
systems by mimicking the biological nervous systems that occur in the human brain. ANN has process nodes with a simple logic connected to each other. Each node has an activation function that collects an input signal, and the aggregated signal is converted to a different value in the specified transformation function. Thus, a converted output signal is generated. Although each function is implemented very slowly by each neuron, a network can effectively carry out an incredible number of tasks [38, 39]. Initial weights are determined randomly at the first iteration, and the output and error of each latent neuron are calculated. The weight change is calculated according to a specific function, and the change is used to update the weights. The next iteration is then performed with respect to the updated weights.

Let $\bar{w}$ be an optimal weight vector, and it is most likely to catch the set of observed target data $y=\left(y_{1}, y_{2}, \ldots, y_{n}\right)$, given the inputs $x=\left(x_{1}, x_{2}, \ldots, x_{n}\right)$ in the Bayesian training approach. $w$ is a vector of connection and bias weights that characterizes the data generating relationship. Bayesian training aims to gather the posterior probability distribution of the weights given the observed data $P(w \mid y, x)$. This process is carried out while updating any knowledge of the weight values before obtaining the data, with the information contained in the data, using Bayes theorem [40].

$$
P(w \mid y, x)=\frac{P(y \mid w, x) * P(w)}{P(y \mid x)} .
$$

The prior weight distribution and the likelihood function are represented, respectively, by $P(w)$ and $P(y \mid w, x)$, respectively. $P(y \mid x)$ shows the prior probability of the training data. The flowchart of Bayesian ANN is shown in Figure 1.

3.2. Genetic Algorithm. GAs have been developed to mimic some of the processes observed in natural evolution [41]. GAs aims to create a competitive set of solutions, and these targeted solutions progress through the natural selection process, in which noneffective solutions emerge and more efficient solutions continue to be reproduced. This process is repeated until the optimal solution set is obtained.

3.2.1. GA-ANN. A hybrid GA-ANN is a backpropagation network, which is the only exception to obtaining the weight matrix from performing genetic processes under optimal convergence conditions [42-44]. The flowchart of GA-ANN is shown in Figure 2. The initial weights are set at random in the first iteration, and the output and error of each latent neuron are calculated. Updated weights are computed according to GA by applying primary selection, reproduction, and mutation. The next iteration is then performed concerning the updated weights. Crossover and mutation operators in GA are used in the selection of weights and result in new offspring weights that offer better fitness value. While the weights are optimized here, the population number, crossover, and mutation values are also tried to be optimized by trial and error.
3.3. Particle Swarm Optimization. The PSO algorithm starts by creating a random population. It refers to a randomly generated population particle, the optimal values of these particles should be determined, and each particle is actually a different decision variable that must represent a vector in the problem-solving area. In the PSO algorithm, the movement of any particle affects the movement of the entire group, and ultimately, each member of the group can benefit from the discoveries and skills of other members $[45,46]$.

3.3.1. PSO-ANN. The PSO algorithm starts with the generation of starting particles, and the starting rates are assigned to the starting particles. At each iteration, each particle is updated based on the best values obtained. The comparison of the obtained values is performed with regard to the fitness value of the relevant iteration and the fitness value obtained so far during the iteration. One of them is the compliance value obtained so far, and this value is kept as the best solution. The other value is the best value reached by any particle in the population. $p_{\text {_ }} p_{-}$best $i$ is $i$ particle's best-known position, and $p_{-g_{\text {b best }}}$ is the best position known to the swarm. The rand variable generates random values between 0 and $1 . C_{1}$ and $C_{2}$ equal to 1 and 2 , respectively. The position values of the particles are obtained by means of the position equation affected by the velocity. Position values represent the weight values of the network. As the fitness function is optimized, the position values, i.e., the weight values of the net, are also optimized. Different combinations are tested on $C_{1}$ and $C_{2}$ parameters to obtain better weight values. The flowchart of PSO-ANN is shown in Figure 3.

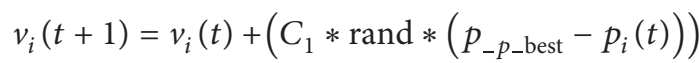

$$
\begin{aligned}
& +\left(C_{2} * \text { rand } *\left(p_{-g \_ \text {best }}-p_{i}(t)\right)\right) .
\end{aligned}
$$

Equation (2) shows the calculation of updating the velocity of the particle.

$$
p_{i}(t+1)=p_{i}(t)+v_{i}(t) .
$$

Equation (3) indicates the calculation of updating the position of the particle for the weights of networks.

\section{Dataset and Analysis}

We used two years' data of a public hospital ED in Istanbul, Turkey. The data belongs to the years 2011 and 2012 (from January 1, 2011, to December 31, 2012). The time series used for modeling is shown in Figure 4. Temporal variables and a climatic variable of maximum temperature were used as dependent variables to forecast the daily ED patient visit. A total of 21 independent variables are used. Binary dummy variables are used in data regarding the month of the year, day of the week, and holiday (weekend holiday). While the value of 0 means that the related date does not belong to that month or that day or weekend holiday, " 1 " means belonging. The dummy variables are utilized in the dataset instead of the original categorical variable. The data for maximum temperature are obtained from a French meteorological association named Infoclimat 


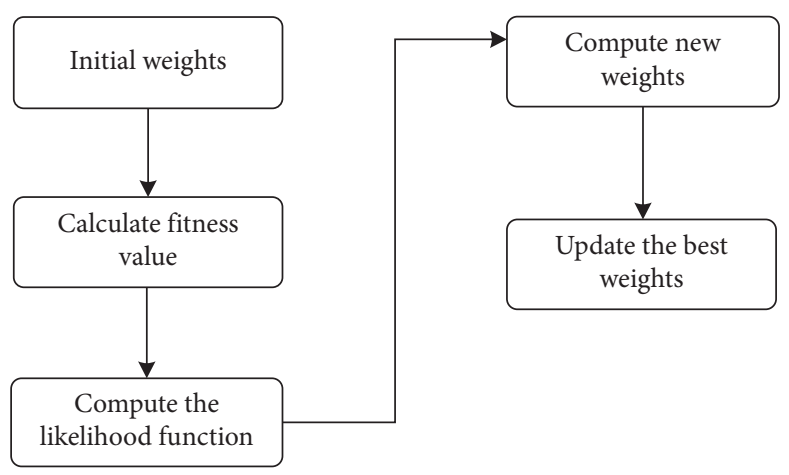

FIgUre 1: The flowchart of Bayesian ANN.

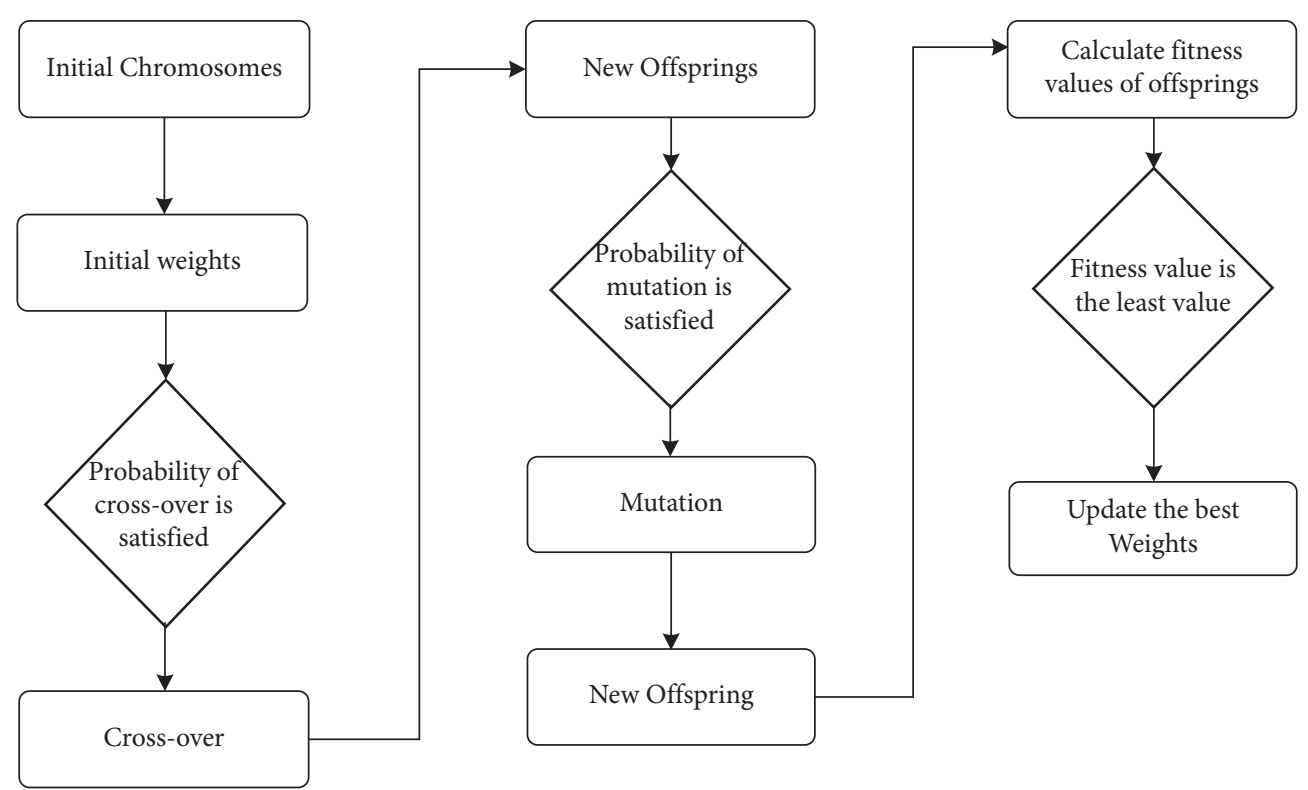

Figure 2: The flowchart of the hybridized GA-ANN.

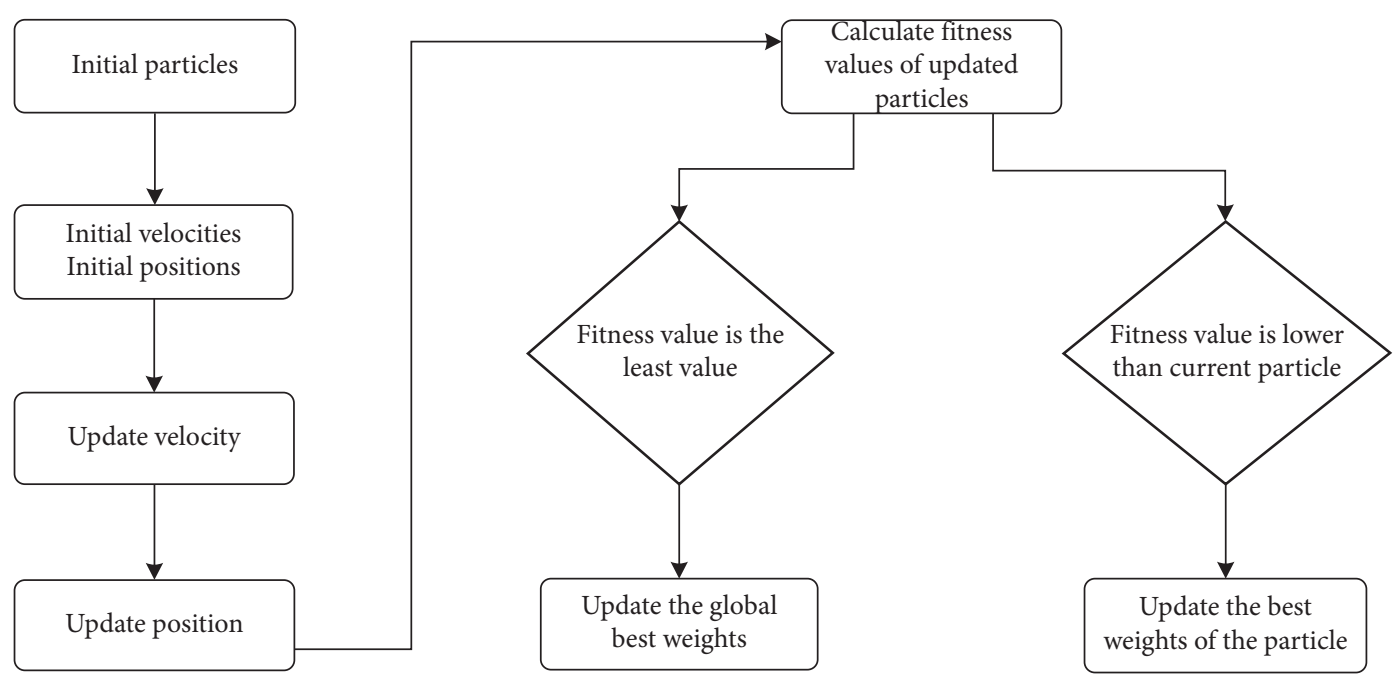

FIgURE 3: The flowchart of the hybridized PSO-ANN. 


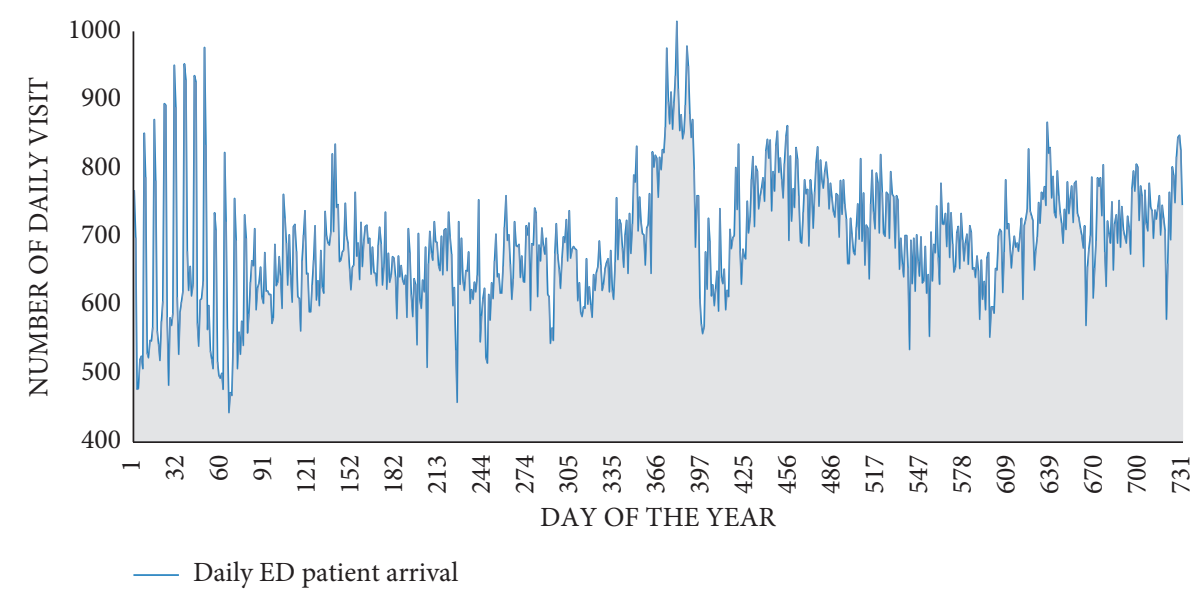

FIgURE 4: Time-series data of the daily ED patient visits (2011-2012).

TABle 1: Descriptive statistics of variables.

\begin{tabular}{|c|c|c|c|c|}
\hline Variable & Unit & Input/output & Total number of variables & Mean (standard deviation) \\
\hline Month of the year & Binary dummy & Input & 12 & - \\
\hline Day of the week & Binary dummy & Input & 7 & - \\
\hline Holiday (weekend) & Binary dummy & Input & 1 & - \\
\hline Maximum temperature $\left({ }^{\circ} \mathrm{C}\right)$ & Numerical & Input & 1 & $19.34(8.98)$ \\
\hline Daily ED patient visit & Numerical & Output & 1 & $692.27(87.66)$ \\
\hline
\end{tabular}

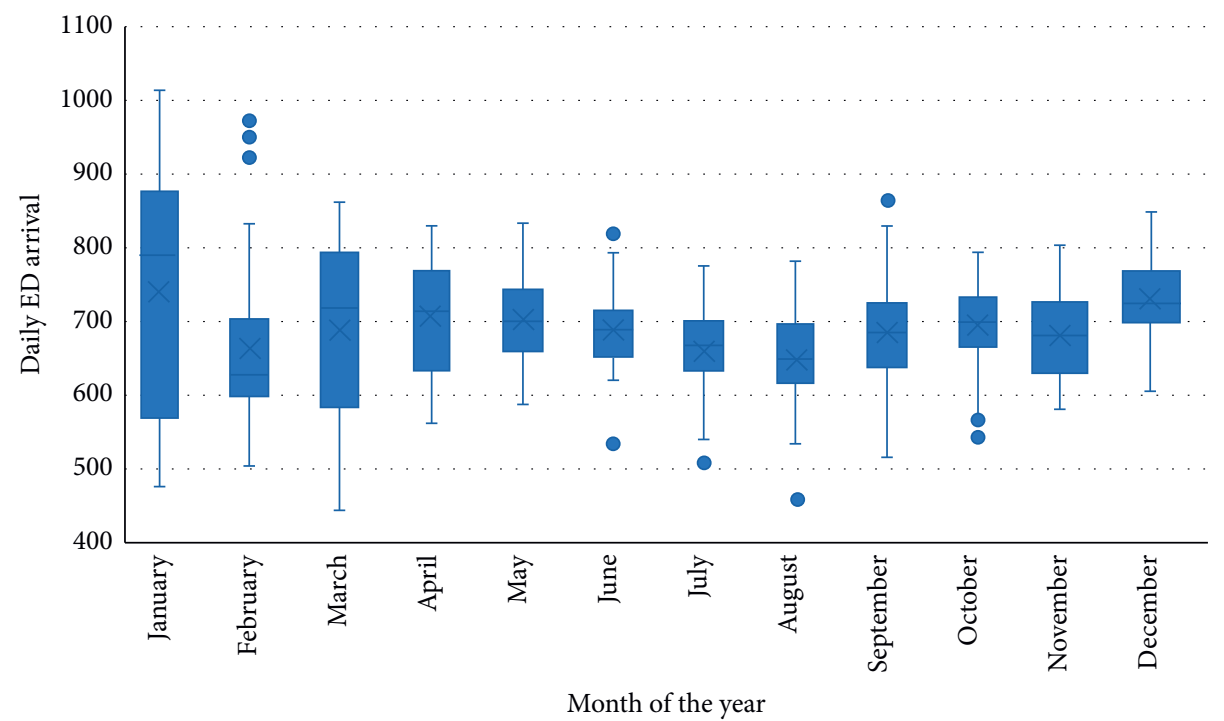

FIgURE 5: Box plot of the daily ED data on the basis of monthly trend.

(http://www.infoclimat.fr). A detailed description for each variable is provided in Table 1. Also, the time-series data of the dependent variable (daily ED visit) are presented in Figure 4. This figure shows that the highest number of visits at the ED occurred on January 14, 2012, with 1013 visits per day. The plot of daily ED visits shows the monthly fluctuations in the ED: there were more patients in January and December; there were slightly fewer patients in August. The trend of monthly ED visits on average is given as a box plot in Figure 5.
Also, the trend of the maximum temperature variable is demonstrated in Figure 6. According to this figure, the average maximum temperature is obtained as $19.34^{\circ} \mathrm{C}$ with a standard deviation of 8.98 .

\section{Results and Discussion}

This paper performs the cross validation to the training dataset to prevent overfitting. It divides the training dataset into ten subsets. One of the ten subsets is held, and the rest of 


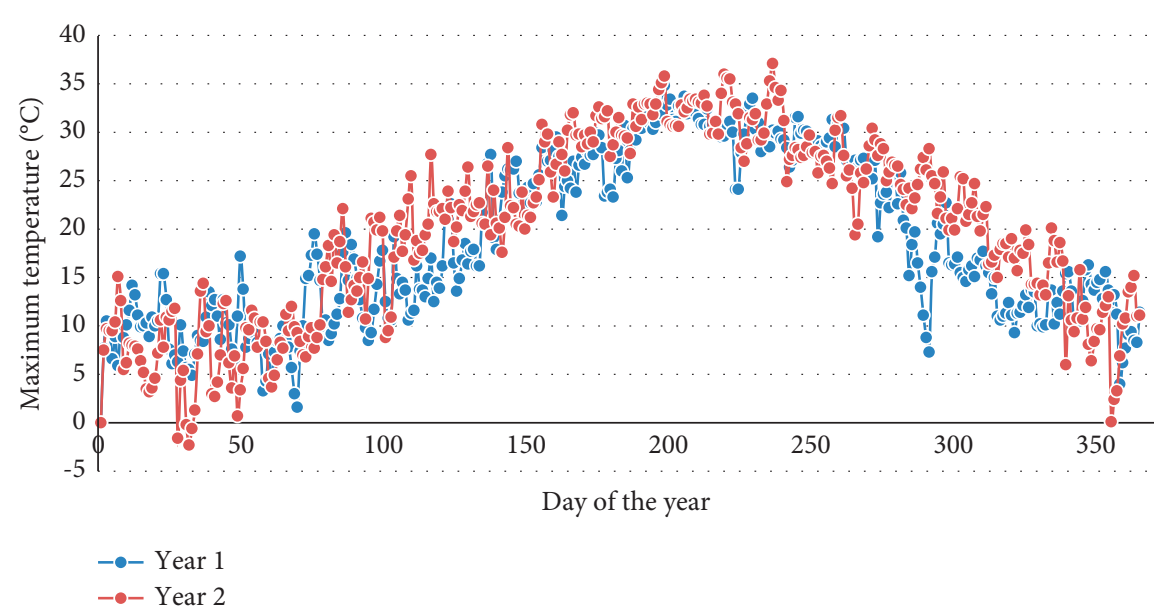

Figure 6: Trend of the maximum temperature $\left({ }^{\circ} \mathrm{C}\right)$ data for the years 2011 and 2012.

TABle 2: The trials for Bayesian ANN for testing.

\begin{tabular}{lccccccccc}
\hline$\# n$ & MSE & $\# n$ & MSE & $\# n$ & MSE & $\# n$ & MSE & $\# n$ & MSE \\
\hline $\mathbf{2}$ & 4911.005 & $\mathbf{1 2}$ & 4841.185 & $\mathbf{2 2}$ & 4806.977 & $\mathbf{3 2}$ & 4851.388 & $\mathbf{4 2}$ & 4813.478 \\
$\mathbf{3}$ & 4835.644 & $\mathbf{1 3}$ & 4806.369 & $\mathbf{2 3}$ & 4862.533 & $\mathbf{3 3}$ & 4936.914 & $\mathbf{4 3}$ \\
$\mathbf{4}$ & 5019.853 & $\mathbf{1 4}$ & 4834.975 & $\mathbf{2 4}$ & 4822.185 & $\mathbf{3 4}$ & 4510.968 & $\mathbf{4 4}$ \\
$\mathbf{5}$ & 4837.925 & $\mathbf{1 5}$ & 4885.426 & $\mathbf{2 5}$ & 4908.832 & $\mathbf{3 5}$ & 4504.176 & $\mathbf{4 5}$ \\
$\mathbf{6}$ & 4928.894 & $\mathbf{1 6}$ & 4939.633 & $\mathbf{2 6}$ & 4941.382 & $\mathbf{3 6}$ & 4981.652 & $\mathbf{4 6}$ & 4892.921 \\
$\mathbf{7}$ & 4781.13 & $\mathbf{1 7}$ & 4781.687 & $\mathbf{2 7}$ & 4883.294 & $\mathbf{3 7}$ & 4534.402 & $\mathbf{4 7}$ & 598.429 \\
$\mathbf{8}$ & 4891.587 & $\mathbf{1 8}$ & 4932.688 & $\mathbf{2 8}$ & 4809.14 & $\mathbf{3 8}$ & 4825.12 & $\mathbf{4 8}$ & 4773.257 \\
$\mathbf{9}$ & 4818.638 & $\mathbf{1 9}$ & 4882.4 & $\mathbf{2 9}$ & 4873.752 & $\mathbf{3 9}$ & 4884.537 & $\mathbf{4 9}$ & 4799.222 \\
$\mathbf{1 0}$ & 4827.339 & $\mathbf{2 0}$ & 4865.005 & $\mathbf{3 0}$ & 4923.553 & $\mathbf{4 0}$ & 4620.716 & $\mathbf{5 0}$ & 4835.748 \\
$\mathbf{1 1}$ & 4885.545 & $\mathbf{2 1}$ & 4867.583 & $\mathbf{3 1}$ & 4659.339 & $\mathbf{4 1}$ & 4838.274 & & \\
\hline
\end{tabular}

the subsets are trained regarding the fitness function. We applied different number of neurons (\#n) for obtaining the best solution in Bayesian ANN. The number of neurons is increased one by one, ranging from 2 to 50. In this process, we used MSE for determining the best number of neurons. While logsig is used in the transfer function, purelin is also applied in the activation function. The minimum MSE is obtained with 45 neurons, and all solutions are presented in Table 2. Then, the results of Bayesian ANN are solved using this combination.

After obtaining the best configuration for Bayesian ANN with respect to the MSE, the results of five performance measures are presented in Table 3 . The results of the training and testing are also illustrated in Figures 7 and 8, respectively.

The obtained MAPE for training and testing for Bayesian ANN is $7.3 \%$ and $8.8 \%$, respectively. The other performance measures are also given in Table 3 .

In the GA-ANN approach, we also applied the different combinations of parameters for obtaining the best solution. The number of populations, crossover rate, mutation rate, and the number of neurons are used. The number of populations is considered as 50. Six different crossover rates are used as $0.4,0.5,0.6,0.7,0.8$, and 0.9 . Four different mutations' rate is also utilized as $0.1,0.2,0.3$, and 0.4 . The number of neurons is increased one by one, ranging from 2
TABLE 3: The results of the performance measures for Bayesian ANN.

\begin{tabular}{lcc}
\hline & Training & Testing \\
\hline MAPE & 0.073 & 0.088 \\
MAE & 50.016 & 60.358 \\
MSE & 4246.407 & 7031.078 \\
RMSE & 65.164 & 83.852 \\
$R^{2}$ & 0.672 & 0.343 \\
\hline
\end{tabular}

to 50 as in Bayesian ANN. The logsig and purelin are used, respectively, in the transfer and activation functions in the ANN process. Therefore, 1176 different solutions $(=: 4 \times 6 \times 49)$ are totally obtained for GA-ANN. The best twenty combinations with respect to MSE are presented in Table 4.

After obtaining the best configuration for GA-ANN with respect to the MSE, the results of five performance measures are presented in Table 5. The results of the training and testing are also illustrated in Figures 9 and 10, respectively. The obtained MAPE for training and testing for GA-ANN are $7.8 \%$ and $6.9 \%$ respectively. The other performance measures are also given in Table 5.

In the PSO-ANN approach, we also applied different combinations of parameters for obtaining the best solution. The number of populations, the weighting coefficient for the 


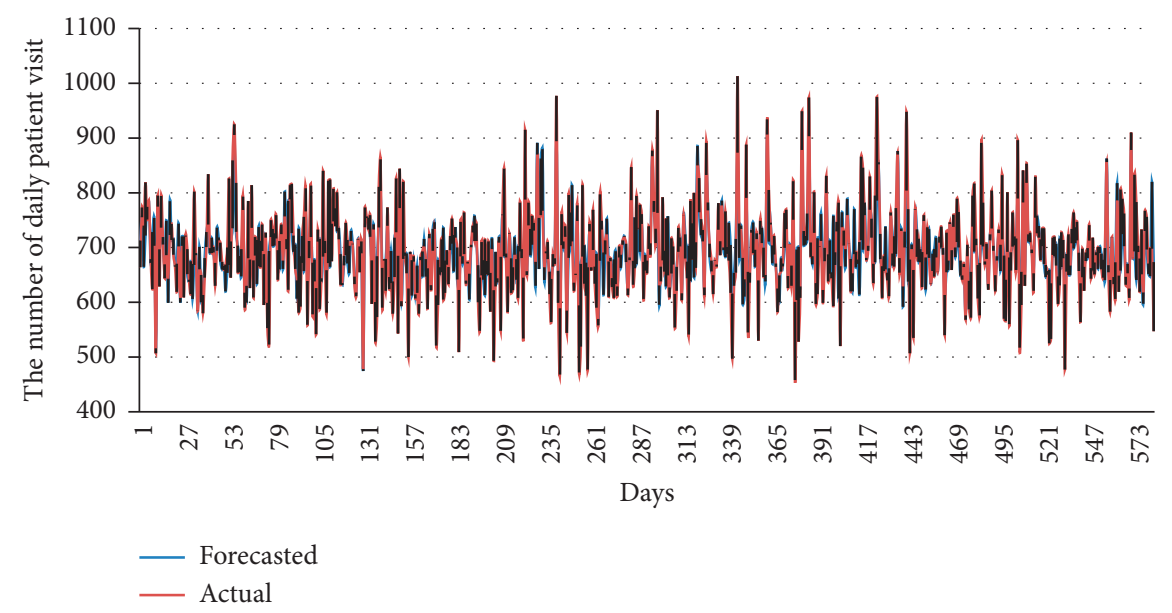

FIgURE 7: The actual and forecasted daily patient visits of Bayesian ANN for training.

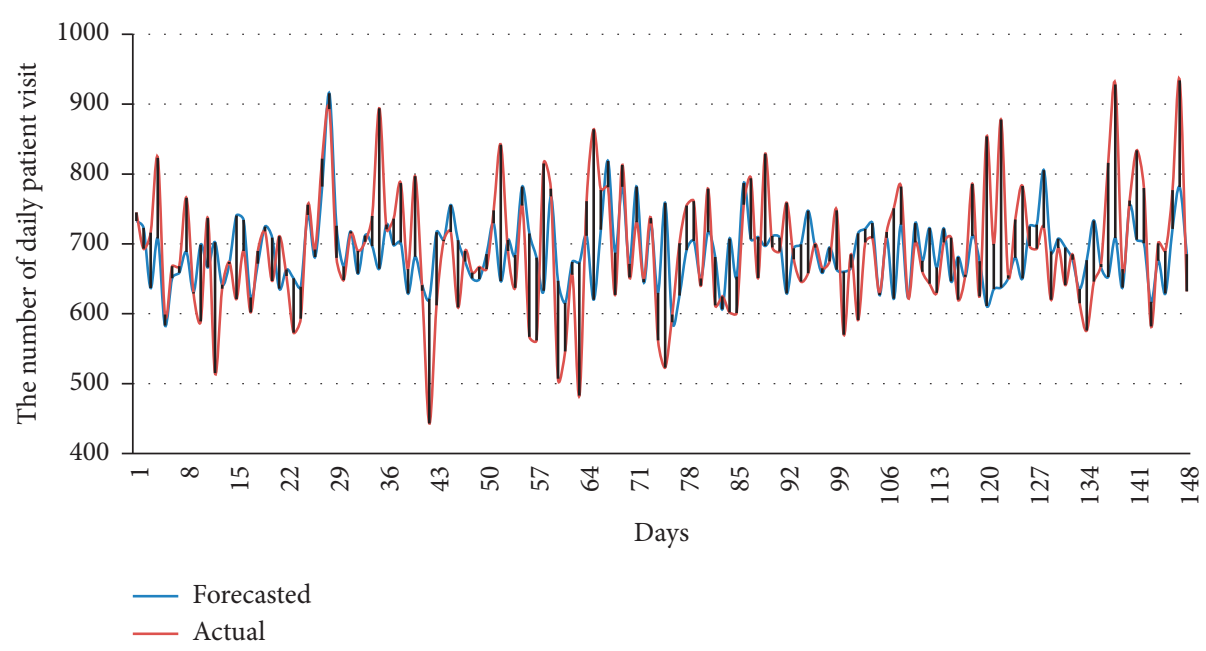

FIgURE 8: The actual and forecasted daily patient visits of Bayesian ANN for testing.

TABLE 4: The trials for GA-ANN for testing.

\begin{tabular}{|c|c|c|c|c|c|c|c|c|c|}
\hline Population & Crossover rate & Mutation rate & $\# n$ & MSE & Population & Crossover rate & Mutation rate & $\# n$ & MSE \\
\hline 50 & 0.8 & 0.1 & 14 & 3765.061 & 50 & 0.6 & 0.2 & 31 & 3809.621 \\
\hline 50 & 0.9 & 0.1 & 41 & 3766.242 & 50 & 0.4 & 0.4 & 11 & 3813.64 \\
\hline 50 & 0.8 & 0.4 & 35 & 3778.22 & 50 & 0.9 & 0.3 & 50 & 3814.467 \\
\hline 50 & 0.7 & 0.3 & 6 & 3778.834 & 50 & 0.8 & 0.2 & 2 & 3814.507 \\
\hline 50 & 0.4 & 0.2 & 4 & 3780.327 & 50 & 0.6 & 0.3 & 42 & 3818.202 \\
\hline 50 & 0.7 & 0.3 & 20 & 3797.909 & 50 & 0.8 & 0.3 & 10 & 3819.057 \\
\hline 50 & 0.7 & 0.4 & 3 & 3800.592 & 50 & 0.7 & 0.4 & 45 & 3820.331 \\
\hline 50 & 0.9 & 0.4 & 37 & 3801.734 & 50 & 0.9 & 0.1 & 11 & 3820.392 \\
\hline 50 & 0.9 & 0.2 & 36 & 3804.538 & 50 & 0.7 & 0.1 & 46 & 3820.961 \\
\hline 50 & 0.9 & 0.3 & 9 & 3808.179 & 50 & 0.8 & 0.1 & 21 & 3822.238 \\
\hline
\end{tabular}

TABLE 5: The results of the performance measures for GA-ANN.

\begin{tabular}{lcc}
\hline & Training & Testing \\
\hline MAPE & 0.078 & 0.069 \\
MAE & 53.183 & 47.643 \\
MSE & 3765.061 & 3321.312 \\
RMSE & 61.360 & 57.631 \\
$R^{2}$ & 0.716 & 0.736 \\
\hline
\end{tabular}

local best solution $(C 1)$, the weighting coefficient for the global best solution (C2), and the number of neurons are used. The number of populations is considered as 50 . Three different weighting coefficients for the local best solution are used as 1.0, 1.5, and 2.0. Nine different weighting coefficients for the global best solution are also utilized that is between 1 and 5 as 0.5 increasing. The number of neurons is increased 


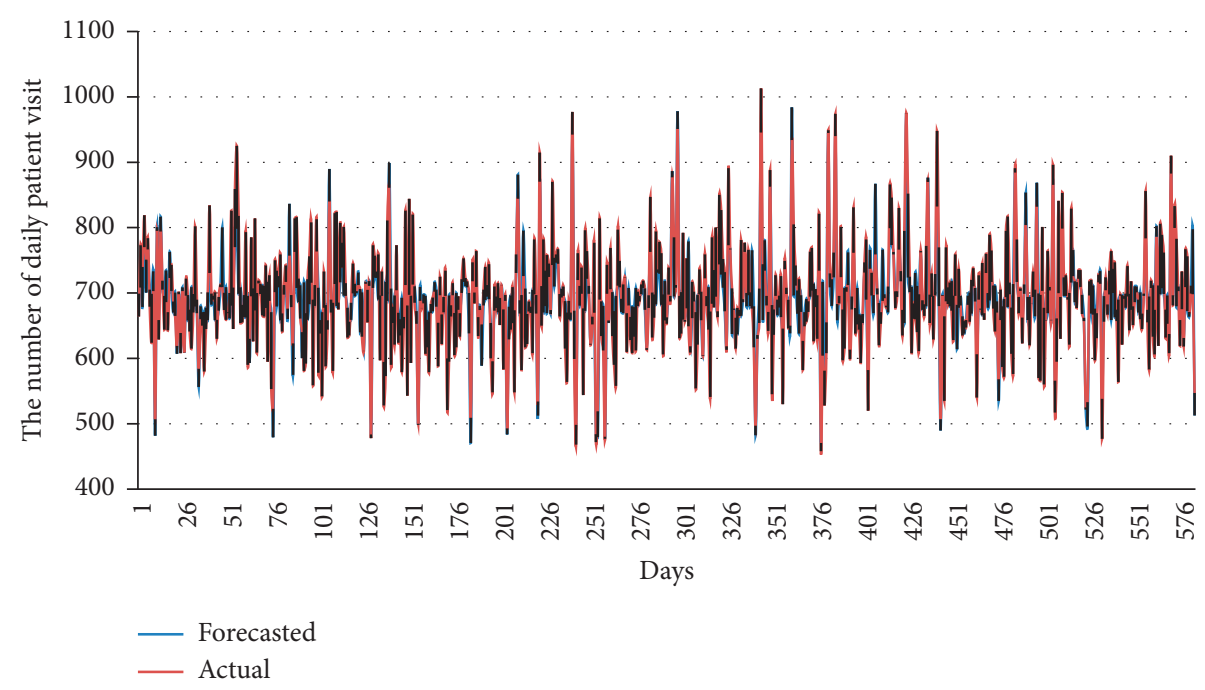

FIGURE 9: The actual and forecasted daily patient visits of GA-ANN for training.

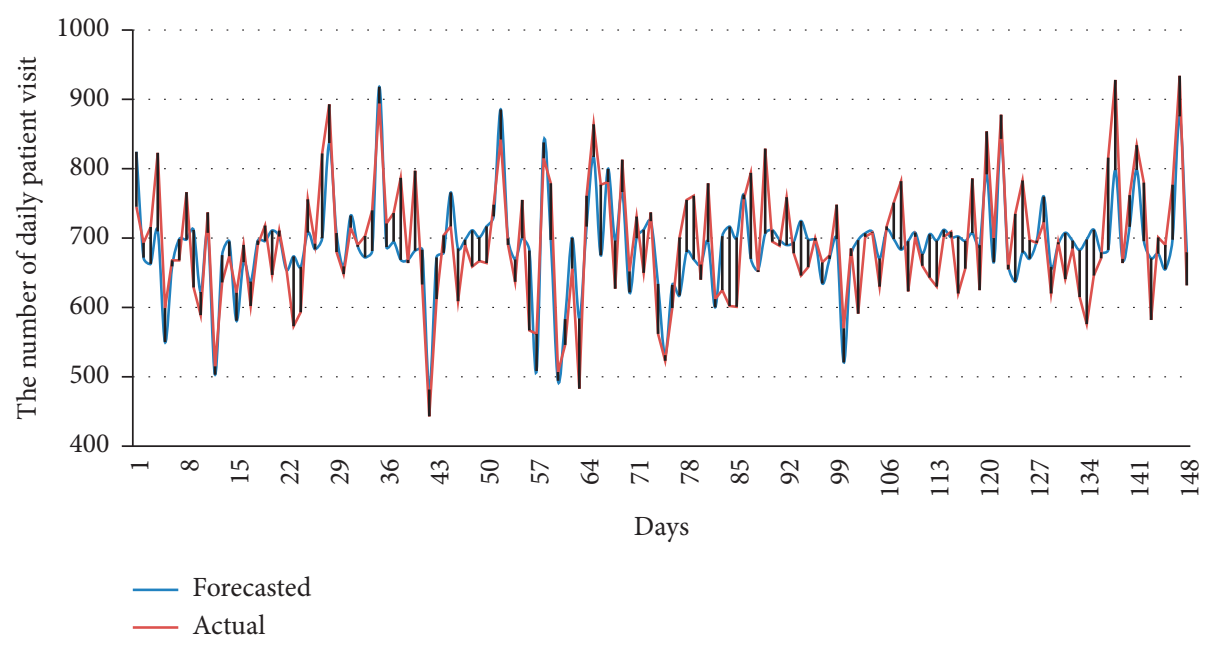

FIGURE 10: The actual and forecasted daily patient visits of GA-ANN for testing.

TABLE 6: The trials for PSO-ANN for the best twenty combinations for testing.

\begin{tabular}{|c|c|c|c|c|c|c|c|c|c|}
\hline Population & $C 1$ & $\mathrm{C} 2$ & $\# n$ & MSE & Population & $C 1$ & $\mathrm{C} 2$ & $\# n$ & MSE \\
\hline 50 & 1 & 1.5 & 25 & 2499.34 & 50 & 1 & 1.5 & 15 & 2653.19 \\
\hline 50 & 1 & 1.5 & 9 & 2554.78 & 50 & 1.5 & 1 & 16 & 2656.31 \\
\hline 50 & 1.5 & 1.5 & 24 & 2569.01 & 50 & 1 & 1.5 & 39 & 2658.15 \\
\hline 50 & 1.5 & 1 & 8 & 2572.10 & 50 & 1 & 1 & 20 & 2661.10 \\
\hline 50 & 1.5 & 1.5 & 10 & 2582.99 & 50 & 1.5 & 1.5 & 5 & 2661.90 \\
\hline 50 & 1 & 1.5 & 11 & 2587.58 & 50 & 1 & 1 & 19 & 2666.78 \\
\hline 50 & 1 & 1.5 & 23 & 2593.40 & 50 & 1.5 & 1 & 31 & 2670.81 \\
\hline 50 & 1 & 1.5 & 19 & 2597.32 & 50 & 1.5 & 1 & 4 & 2672.37 \\
\hline 50 & 1 & 1.5 & 27 & 2614.94 & 50 & 1.5 & 1 & 29 & 2673.48 \\
\hline 50 & 1 & 2 & 10 & 2620.29 & 50 & 1 & 1 & 17 & 2676.55 \\
\hline 50 & 1.5 & 1.5 & 11 & 2626.79 & 50 & 1.5 & 1.5 & 8 & 2679.84 \\
\hline 50 & 1 & 1.5 & 20 & 2642.21 & 50 & 1 & 1.5 & 16 & 2680.05 \\
\hline 50 & 1.5 & 1.5 & 12 & 2647.97 & & & & & \\
\hline
\end{tabular}


TABLE 7: The results of the performance measures for PSO-ANN.

\begin{tabular}{lcc}
\hline & Training & Testing \\
\hline MAPE & 0.063 & 0.069 \\
MAE & 42.797 & 47.643 \\
MSE & 2499.340 & 3321.312 \\
RMSE & 49.993 & 57.631 \\
$R^{2}$ & 0.824 & 0.736 \\
\hline
\end{tabular}

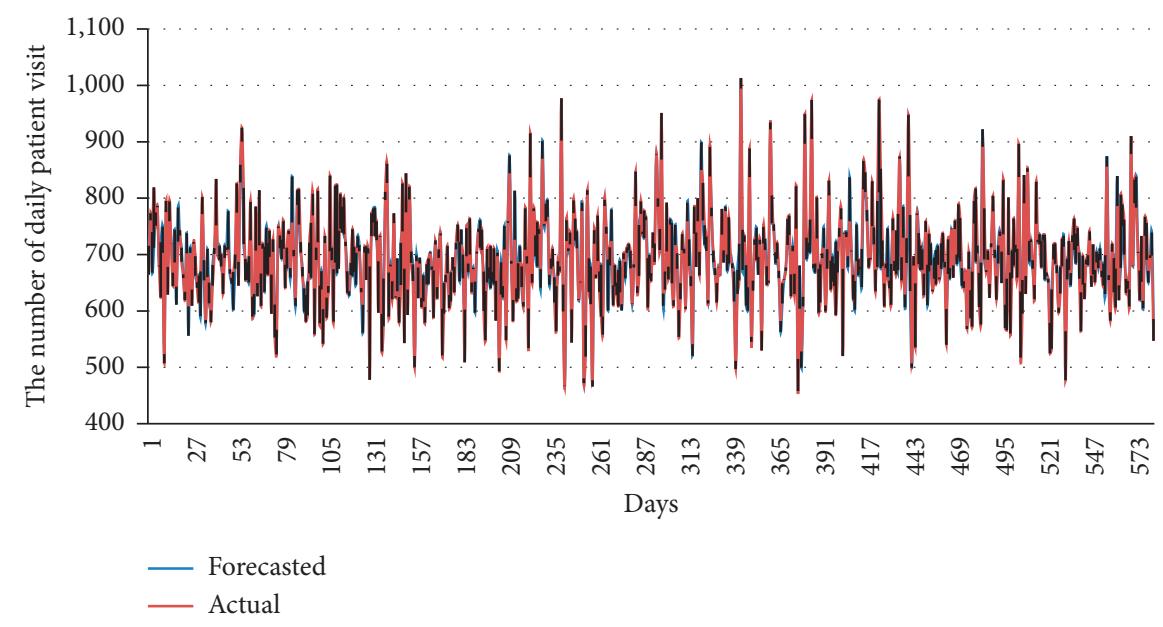

FIgURE 11: The actual and forecasted daily patient visits of PSO-ANN for training.

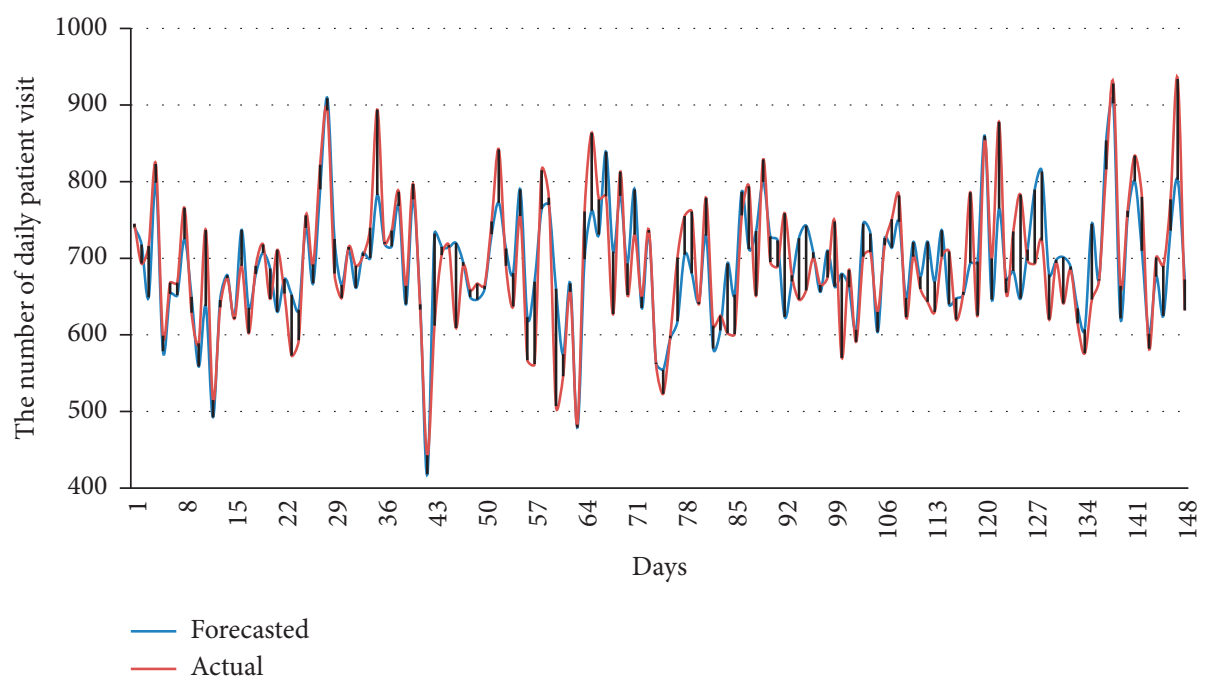

FIgURE 12: The actual and forecasted daily patient visits of PSO-ANN for testing.

one by one, ranging from 2 to 50 as in PSO-ANN. In the ANN process, the tansig are used for both transfer and activation functions. Therefore, 1182 different solutions are obtained for PSO-ANN. The best twenty combinations with respect to MSE are presented in Table 6.

After obtaining the best configuration for PSO-ANN with respect to the MSE, the results of five performance measures are presented in Table 7 . The results of the training and testing are also illustrated in Figures 11 and 12, respectively. The obtained MAPE for training and testing for PSO-ANN is $6.3 \%$ and $6.9 \%$, respectively. The other performance measures are also given in Table 7.

After the models are implemented for the forecasting of daily patient visits in emergency departments, their results are compared and evaluated together through the performance measures. A detailed evaluation of the proposed models based on both training and the testing dataset is implemented in this section. Table 8 presents the forecasting 
TABLE 8: The results of three approaches in training and testing processes.

\begin{tabular}{|c|c|c|c|c|c|c|c|c|c|c|}
\hline & \multicolumn{10}{|c|}{ Training } \\
\hline & MAPE & Rank & MAE & Rank & MSE & Rank & RMSE & Rank & $R^{2}$ & Rank \\
\hline Bayesian ANN & 0.073 & 2 & 50.016 & 2 & 4246.407 & 3 & 65.164 & 3 & 0.672 & 3 \\
\hline GA-ANN & 0.078 & 3 & 53.183 & 3 & 3765.061 & 2 & 61.360 & 2 & 0.716 & 2 \\
\hline \multirow[t]{3}{*}{ PSO-ANN } & 0.063 & 1 & 42.797 & 1 & 2499.340 & 1 & 49.993 & 1 & 0.824 & 1 \\
\hline & \multicolumn{10}{|c|}{ Testing } \\
\hline & MAPE & Rank & MAE & Rank & MSE & Rank & RMSE & Rank & $R^{2}$ & Rank \\
\hline Bayesian ANN & 0.088 & 3 & 60.358 & 3 & 7031.078 & 3 & 83.852 & 3 & 0.343 & 3 \\
\hline GA-ANN & 0.069 & 2 & 47.643 & 2 & 3321.312 & 2 & 57.631 & 2 & 0.736 & 2 \\
\hline PSO-ANN & 0.060 & 1 & 40.888 & 1 & 2839.998 & 1 & 53.292 & 1 & 0.791 & 1 \\
\hline
\end{tabular}

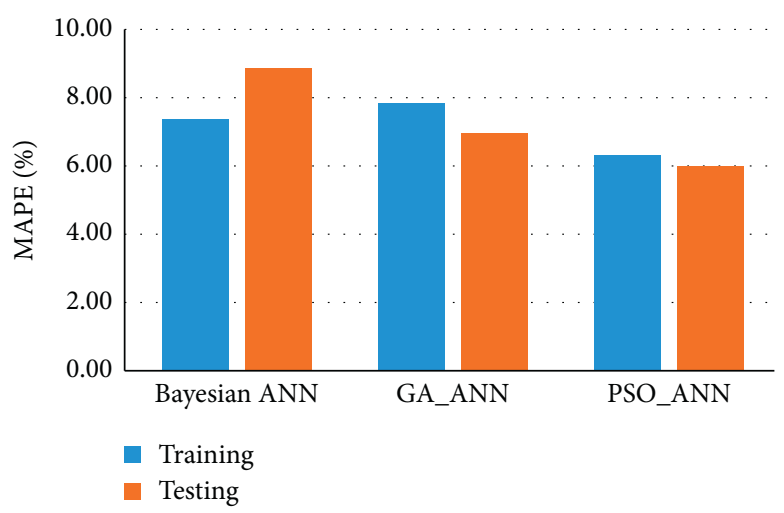

(a)

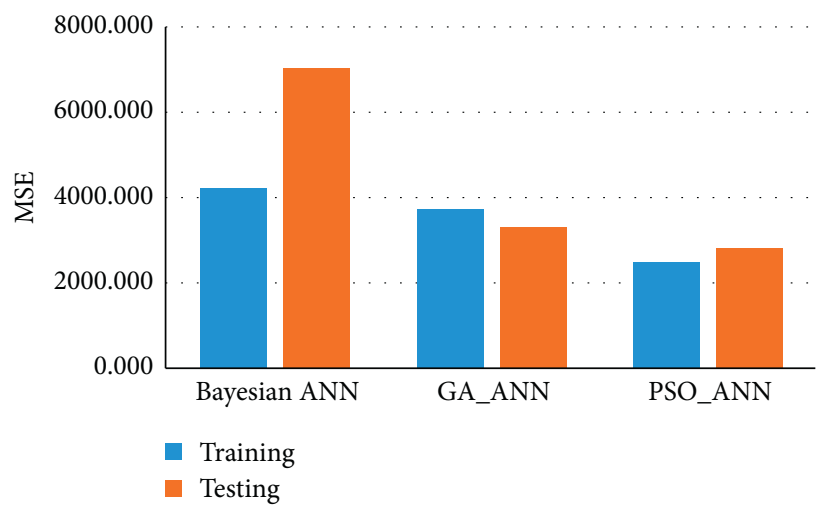

(c)

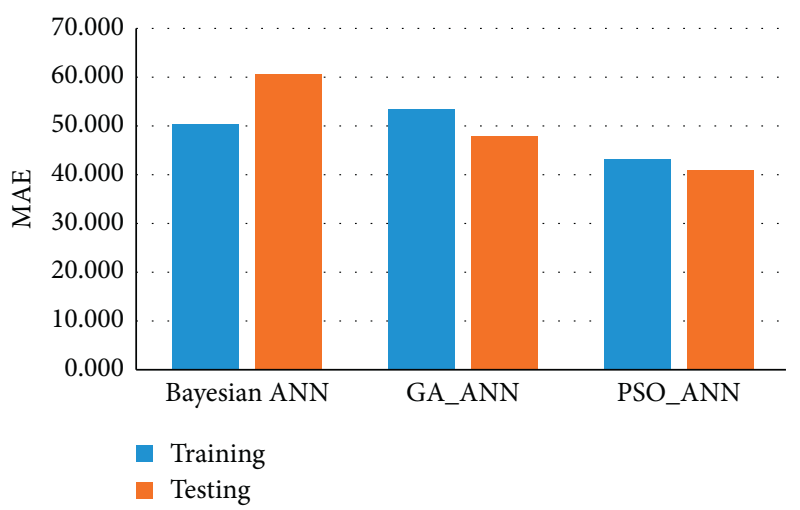

(b)

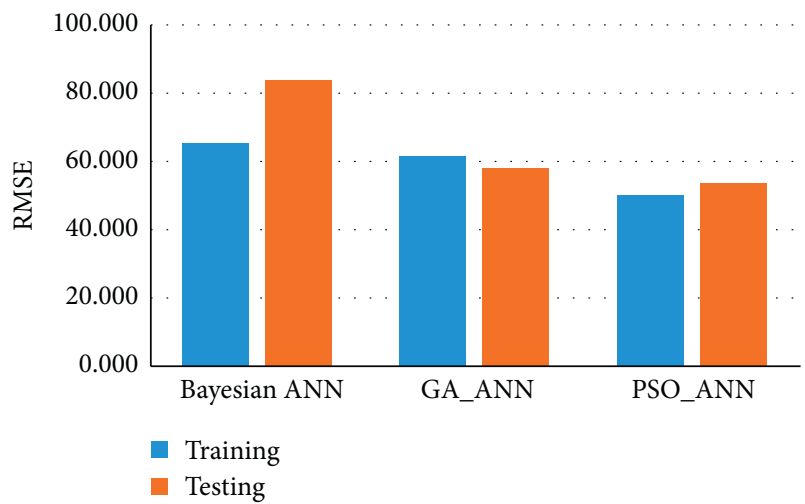

(d)

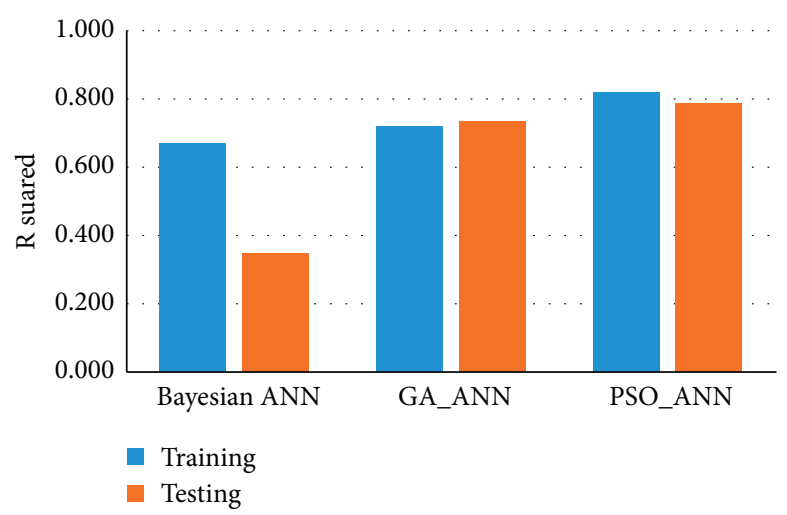

(e)

FiguRE 13: The comparison of approaches with respect to five performance measures: (a) MAPE, (b) MAE, (c) MSE, (d) RMSE, and (e) $R$-squared. 
TABle 9: Comparison of previous studies from the literature.

\begin{tabular}{|c|c|c|c|c|c|c|c|}
\hline Study & Data & Method(s) & $\begin{array}{l}\text { Compared } \\
\text { methods }\end{array}$ & $\begin{array}{l}\text { Time } \\
\text { frame }\end{array}$ & Variables & $\begin{array}{l}\text { Performance } \\
\text { measure }\end{array}$ & Results \\
\hline $\begin{array}{l}\text { Choudhury } \\
\text { and Urena } \\
{[6]}\end{array}$ & $\begin{array}{c}\text { Data from } \\
\text { January } 2014 \\
\text { to August } \\
2017\end{array}$ & $\begin{array}{c}\text { TBATS, } \\
\text { Holt-Winters, } \\
\text { neural net, and } \\
\text { ARIMA }\end{array}$ & - & Hourly & $\begin{array}{l}\text { Only temporal } \\
\text { variables }\end{array}$ & ME and RMSE & $\begin{array}{l}1.75,1.19,1.40 \text {, and } \\
1.00 \text { (ME for each } \\
\text { model, } \\
\text { respectively); 2.28, } \\
27.86,3.26, \text { and } \\
1.55 \text { (RMSE for } \\
\text { each model, } \\
\text { respectively) }\end{array}$ \\
\hline $\begin{array}{l}\text { Yousefi et al. } \\
{[20]}\end{array}$ & $\begin{array}{c}\text { Data from } \\
\text { January } 2014 \\
\text { to November } \\
2016\end{array}$ & $\begin{array}{l}\text { Long short-term } \\
\text { memory (LSTM) }\end{array}$ & $\begin{array}{l}\text { MLR, ARIMA, } \\
\text { SVR, GLM, GEE, } \\
\text { SARIMA, and } \\
\text { ARIMA-LR }\end{array}$ & Daily & $\begin{array}{l}\text { Weekend, } \\
\text { holiday, soccer } \\
\text { match day, the } \\
\text { day after } \\
\text { holiday, and the } \\
\text { day before } \\
\text { holiday }\end{array}$ & $\begin{array}{l}\text { MAPE and } R- \\
\text { squared }\end{array}$ & $\begin{array}{c}5.55 \%(\mathrm{MAPE}) \text { and } \\
0.940 \text { ( } R \text {-squared })\end{array}$ \\
\hline $\begin{array}{l}\text { Zhang et al. } \\
{[26]}\end{array}$ & $\begin{array}{l}\text { Data from } \\
\text { January 1, } \\
2013 \text {, to } \\
\text { December } 31 \text {, } \\
2016\end{array}$ & $\begin{array}{c}\text { ARIMA-SVR } \\
\text { hybrid approach }\end{array}$ & ARIMA and SVR & Daily & $\begin{array}{l}\text { Only temporal } \\
\text { variables }\end{array}$ & $\begin{array}{l}\text { MAPE, RMSE, } \\
\text { and MAE }\end{array}$ & $\begin{array}{c}7.02 \% \text { (MAPE), } \\
19.20 \text { (RMSE), and } \\
14.97 \text { (MAE) }\end{array}$ \\
\hline $\begin{array}{l}\text { Jilani et al. } \\
\text { [23] }\end{array}$ & $\begin{array}{l}\text { Data between } \\
\text { Jan } 2011 \text { and } \\
\text { December } \\
2015 \text { from } \\
\text { four hospitals }\end{array}$ & $\begin{array}{c}\text { A modified } \\
\text { heuristics based } \\
\text { on a fuzzy time- } \\
\text { series model }\end{array}$ & ARIMA and ANN & $\begin{array}{l}\text { Weekly } \\
\text { and } \\
\text { monthly }\end{array}$ & $\begin{array}{l}\text { Only temporal } \\
\text { variables }\end{array}$ & $\begin{array}{l}\text { MAPE and } \\
\text { RMSE }\end{array}$ & $\begin{array}{c}2.5 \% \text { to } 7 \% \\
\text { (MAPE-daily) and } \\
2.09 \% \text { to } 2.81 \% \\
\text { (MAPE-monthly) }\end{array}$ \\
\hline $\begin{array}{l}\text { Khaldi et al. } \\
{[14]}\end{array}$ & $\begin{array}{l}\text { Seven years of } \\
\text { aggregated } \\
\text { weekly } \\
\text { demand from } \\
2010 \text { to } 2016\end{array}$ & $\begin{array}{l}\text { ANN with } \\
\text { ensemble } \\
\text { empirical mode } \\
\text { decomposition } \\
\text { (EEMD) }\end{array}$ & $\begin{array}{l}\text { ANN with discrete } \\
\text { wavelet transform } \\
\text { (DWT) } \\
\text { decomposition, } \\
\text { ANN, and ARIMA }\end{array}$ & Weekly & $\begin{array}{l}\text { Only temporal } \\
\text { variables }\end{array}$ & $\begin{array}{l}\text { RMSE, MAE, } \\
\text { and } R \\
\text { (correlation } \\
\text { coefficient) }\end{array}$ & $\begin{array}{c}52.86(\mathrm{RMSE}), \\
39.88 \text { (MAE), and } \\
0.96(R)\end{array}$ \\
\hline $\begin{array}{l}\text { Tideman } \\
\text { et al. [31] }\end{array}$ & $\begin{array}{l}\text { Seven years of } \\
\text { historical } \\
\text { daily ED } \\
\text { arrivals }\end{array}$ & $\begin{array}{c}\text { Least absolute } \\
\text { shrinkage and } \\
\text { selection operator } \\
\text { (LASSO) } \\
\text { regression }\end{array}$ & 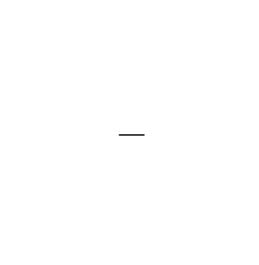 & Daily & $\begin{array}{c}\text { Climatic } \\
\text { variables, } \\
\text { Google trends, } \\
\text { and calendar } \\
\text { variables }\end{array}$ & $\begin{array}{l}\text { MAPE, RMSE, } \\
R \text {-squared, and } \\
\text { percent } \\
\text { absolute } \\
\text { percent error } \\
\text { (PAPE) }\end{array}$ & $\begin{array}{c}7.58 \% \text { to } 10.99 \% \\
\text { (MAPE), } 12.08 \text { to } \\
16.73 \text { (RMSE), } 0.13 \\
\text { to } 0.57 \text { ( } R- \\
\text { squared), and } \\
3.29 \% \text { to } 11.23 \% \\
\text { (PAPE) }\end{array}$ \\
\hline $\begin{array}{l}\text { Carvalho- } \\
\text { Silva et al. } \\
{[22]}\end{array}$ & $\begin{array}{l}\text { Data for ED } \\
\text { arrivals in } 2 \\
\text { years (2012- } \\
2013)\end{array}$ & ARIMA & $\begin{array}{l}\text { Moving average, } \\
\text { multiplicative } \\
\text { winters, } \\
\text { Holt-Winters, and } \\
\text { exponential } \\
\text { smoothing }\end{array}$ & Daily & $\begin{array}{l}\text { Only temporal } \\
\text { variables }\end{array}$ & MAPE & $\begin{array}{l}5.92 \% \text { to } 10.63 \% \\
\text { (MAPE) }\end{array}$ \\
\hline Sarıyer [11] & $\begin{array}{c}\text { Data between } \\
01 / 12 / 2016 \\
\text { and } 28 / 02 / \\
2017\end{array}$ & ARIMA & - & Daily & $\begin{array}{l}\text { Only temporal } \\
\text { variables }\end{array}$ & MAPE & $\begin{array}{l}5.01 \% \text { to } 8.16 \% \\
\text { (MAPE) }\end{array}$ \\
\hline $\begin{array}{l}\text { Juang et al. } \\
\text { [15] }\end{array}$ & $\begin{array}{l}\text { Monthly ED } \\
\text { visits from } \\
\text { January } 2009 \\
\text { to December } \\
2016\end{array}$ & ARIMA & - & Monthly & $\begin{array}{l}\text { Only temporal } \\
\text { variables }\end{array}$ & MAPE & 8.91\% (MAPE) \\
\hline Xu et al. [27] & $\begin{array}{l}\text { Daily ED } \\
\text { visits from } \\
\text { January 1, } \\
\text { 2012, to } \\
\text { December 31, } \\
2013\end{array}$ & $\begin{array}{c}\text { ARIMA-LR } \\
\text { hybrid approach }\end{array}$ & $\begin{array}{l}\text { GLM, ARIMA, } \\
\text { ARIMAX, and } \\
\text { ARIMA-ANN }\end{array}$ & Daily & $\begin{array}{l}\text { Calendar, } \\
\text { holiday and } \\
\text { temperature } \\
\text { variables }\end{array}$ & $\begin{array}{l}\text { MAPE and } \\
\text { RMSE }\end{array}$ & $\begin{array}{c}6.5 \% \text { to } 9.3 \% \\
\text { (MAPE of ED-1), } \\
12.3 \% \text { to } 13.1 \% \\
\text { (MAPE of ED-2), } \\
67.1 \text { to } 98.2 \text { (RMSE } \\
\text { of ED-1), and } 5.49 \\
\text { to } 5.73 \text { (RMSE of } \\
\text { ED-2) }\end{array}$ \\
\hline
\end{tabular}


TABle 9: Continued.

\begin{tabular}{|c|c|c|c|c|c|c|c|}
\hline Study & Data & Method(s) & $\begin{array}{c}\text { Compared } \\
\text { methods }\end{array}$ & $\begin{array}{l}\text { Time } \\
\text { frame }\end{array}$ & Variables & $\begin{array}{c}\text { Performance } \\
\text { measure }\end{array}$ & Results \\
\hline $\begin{array}{l}\text { Calegari } \\
\text { et al. [28] }\end{array}$ & $\begin{array}{l}\text { Period from } \\
\text { January 1, } \\
\text { 2013, to May } \\
\text { 31, 2015 }\end{array}$ & $\begin{array}{l}\text { SS, SMHW, } \\
\text { SARIMA, and } \\
\text { MSARIMA }\end{array}$ & - & Daily & $\begin{array}{c}\text { Calendar and } \\
\text { climatic } \\
\text { variables }\end{array}$ & MAPE & $\begin{array}{l}2.91 \% \text { to } 11.16 \% \\
\text { (MAPE) }\end{array}$ \\
\hline $\begin{array}{l}\text { Current } \\
\text { study }\end{array}$ & $\begin{array}{c}\text { Two years' } \\
\text { data from } \\
\text { January 1, } \\
2011 \text {, to } \\
\text { December } 31 \text {, } \\
2012\end{array}$ & $\begin{array}{c}\text { Bayesian ANN, } \\
\text { GA-based ANN, } \\
\text { and PSO-based } \\
\text { ANN }\end{array}$ & - & Daily & $\begin{array}{l}\text { Calendar, } \\
\text { holiday, and } \\
\text { temperature } \\
\text { variables }\end{array}$ & $\begin{array}{l}\text { MAPE, MAE, } \\
\text { MSE, RMSE, } \\
\text { and } R \text {-squared }\end{array}$ & $\begin{array}{c}6 \% \text { to } 8.8 \% \\
\text { (MAPE), } 40.888 \text { to } \\
60.358 \text { (MAE), } \\
2499.340 \text { to } \\
7031.078 \text { (MSE), } \\
49.993 \text { to } 83.852 \\
\text { (RMSE), and } 0.343 \\
\text { to } 0.824 \text { ( } R- \\
\text { squared) }\end{array}$ \\
\hline
\end{tabular}

results of daily patient visits by the metaheuristic approaches integrated with ANN. The results of the performance measures are also illustrated in Figure 13. From Table 8, it can be seen that the PSO-ANN model provided the most dominant performance in the both the training and testing process. It obtained the lowest error with an MAPE of $6.3 \%$, MAE of 42.797, MSE of 2499.340, RMSE of 49.933, and $R^{2}$ of 0.824 on the training dataset. It also obtained the lowest error with an MAPE of $6.0 \%$, MAE of 40.888 , MSE of 2839.998, RMSE of 53.292, and $R^{2}$ of 0.791 on the testing dataset. The Bayesian ANN and GA-ANN metaheuristics algorithms yielded lower performance in the ANN model optimization in the training process. The weakest model in this optimization process is the Bayesian ANN for both the training and testing process.

As a creative contribution to the literature, a comparison with some previously published papers is performed to highlight the studies in terms of data, applied method(s), compared methods, time frame, independent variables, performance measures, and analysis results. A total of twelve studied including the current study are investigated under these dimensions. Most of the studies focus on the daily basis of ED visits. Some studies tackle the hourly [6], weekly $[14,23]$, and monthly trend of $\operatorname{ED}$ visits $[15,23]$. The datagathering period varied from one study to another. The current study used two years' data of daily arrivals. In light of the eleven studies from the literature summarized in Table 9, it is understood that the data collection period of the current study is sufficient. When analyzing the methodology used, the current study bridges the gap of the literature. Since it does not show any attempts that apply metaheuristics incorporated with ANN in forecasting daily ED visits, this study has novelty for this application domain.

In the work of Wargon et al. [17], variability in MAPE and RMSE ranging from $4.2 \%$ to $14.4 \%$ is considered acceptable in ED daily visit forecasting studies. In this context, the approaches used in the current study meet the criteria. The MAPE values obtained from the three approaches are between $6 \%$ and $8.8 \%$ that means acceptable.

\section{Conclusions}

In this study, we apply three approaches named Bayesian ANN, GA-based ANN, and PSO-based ANN to the daily ED visit forecasting problem. Two years of daily ED visit data are gathered to use in these models. Temporal, climatic, and holiday variables are used in the models as independent variables. Results of each model are analyzed under five different performance measures called MAPE, MAE, MSE, RMSE, and $R$-squared. Results of the approaches show that PSO-based ANN is superior according to all five performance measures. GA-based ANN yields more successful results compared to the Bayesian ANN model. We conclude that the use of metaheuristics integrated with ANN in ED visit forecasting improves the accuracy of the model considerably. The proposed approaches eliminate the problem of getting stuck in local extremums and crossing plateaus of the error function in classical ANN. The initial weights of the ANN are computed using GA and ANN instead of the trial and error process. There are some limitations. Firstly, the data come from only one institution and consist of two-year data. Second, the input variables for ED data are all generally utilized for model parameters in the ED literature. However, the number of parameters can be enriched to improve the accuracy of proposed approaches. Thirdly, the number of analyzed parameters of proposed approaches (Bayesian ANN, GA-ANN, and PSO-ANN) are limited. We have obtained a total of 2497 solutions with respect to the proposed approaches. A parameter optimization for the proposed approaches can be implemented. For future work, we plan to include more variables in our models and compare the performance of current models with some time-series and machine learning algorithms. This study is novel in the literature from the aspect of applying hybrid metaheuristicsbased approaches for the first time. Findings of the current research will also contribute to $\mathrm{ED}$ decision makers in the practice to plan and schedule medical staff to reach an efficient resource planning and service quality. 


\section{Data Availability}

No data were used to support this study.

\section{Conflicts of Interest}

The authors declare no conflicts of interest.

\section{References}

[1] S.-Y. Lee, R. B. Chinnam, E. Dalkiran, S. Krupp, and M. Nauss, "Prediction of emergency department patient disposition decision for proactive resource allocation for admission," Health Care Management Science, vol. 23, no. 3, pp. 339-359, 2020.

[2] D. Bouzon Nagem Assad and T. Spiegel, "Improving emergency department resource planning: a multiple case study," Health Systems, vol. 9, no. 1, pp. 2-30, 2020.

[3] H. T. Karsanti, I. Ardiyanto, and L. E. Nugroho, "Deep learning-based patient visits forecasting using long short term memory," in Proceedings of the 2019 International Conference of Artificial Intelligence and Information Technology (ICAIIT), pp. 344-349, IEEE, Yogyakarta, Indonesia, March 2019.

[4] J. Berglind, "Temporal convolutional networks for forecasting of patient volumes in a digital healthcare setting," Degree Project in Computer Science and Engineering, Second Cycle, Stockholm, Sweden, 2019.

[5] M. Gul and E. Celik, "An exhaustive review and analysis on applications of statistical forecasting in hospital emergency departments," Health Systems, vol. 9, no. 4, pp. 263-284, 2020.

[6] A. Choudhury and E. Urena, "Forecasting hourly emergency department arrival using time series analysis," British Journal of Healthcare Management, vol. 26, no. 1, pp. 34-43, 2020.

[7] M. Hertzum, "Forecasting hourly patient visits in the emergency department to counteract crowding," The Ergonomics Open Journal, vol. 10, no. 1, pp. 1-13, 2017.

[8] M. Ordu, E. Demir, and C. Tofallis, "A decision support system for demand and capacity modelling of an accident and emergency department," Health Systems, vol. 9, no. 1, pp. 31-56, 2020.

[9] M. Ordu, E. Demir, and C. Tofallis, "A comprehensive modelling framework to forecast the demand for all hospital services," The International Journal of Health Planning and Management, vol. 34, no. 2, pp. e1257-e1271, 2019.

[10] E. Pekel, M. Gul, and E. Celik, "Forecasting daily patient visits in an emergency department by GA-ANN hybrid approach," in Proceedings of the 14th International Symposium on Operational Research, pp. 473-478, SOR, Slovenia, Bled, September 2017.

[11] G. Sariyer, "Acil servislerde talebin zaman serileri modelleri ile tahmin edilmesi," Uluslararası Mühendislik Araştırma ve Geliştirme Dergisi, vol. 10, no. 1, pp. 66-77, 2018.

[12] M. Yucesan, M. Gul, and E. Celik, "A multi-method patient arrival forecasting outline for hospital emergency departments," International Journal of Healthcare Management, vol. 13 , no. 1 .

[13] M. Yucesan, M. Gul, S. Mete, and E. Celik, "A forecasting model for patient arrivals of an emergency department in healthcare management systems," in Intelligent Systems for Healthcare Management and Delivery, pp. 266-284, IGI Global, Hershey, PA, USA, 2019.

[14] R. Khaldi, A. E. Afia, and R. Chiheb, "Forecasting of weekly patient visits to emergency department: real case study," Procedia Computer Science, vol. 148, pp. 532-541, 2019.
[15] W.-C. Juang, S.-J. Huang, F.-D. Huang, P.-W. Cheng, and S.-R. Wann, "Application of time series analysis in modelling and forecasting emergency department visits in a medical centre in southern Taiwan," BMJ open, vol. 7, no. 11, Article ID e018628, 2017.

[16] M. Gul and A. F. Guneri, "Planning the future of emergency departments: forecasting ED patient arrivals by using regression and neural network models," International Journal of Industrial Engineering: Theory, Applications and Practice, vol. 23, no. 2, pp. 137-154, 2016.

[17] M. Wargon, B. Guidet, T. D. Hoang, and G. Hejblum, "A systematic review of models for forecasting the number of emergency department visits," Emergency Medicine Journal, vol. 26, no. 6, pp. 395-399, 2009.

[18] F. Kadri, F. Harrou, S. Chaabane, and C. Tahon, “Time series modelling and forecasting of emergency department overcrowding," Journal of Medical Systems, vol. 38, no. 9, p. 107, 2014.

[19] S. Nas and M. Koyuncu, "Emergency department capacity planning: a recurrent neural network and simulation approach," Computational and Mathematical Methods in Medicine, vol. 2019, Article ID 4359719, 13 pages, 2019.

[20] M. Yousefi, M. Yousefi, M. Fathi, and F. S. Fogliatto, "Patient visit forecasting in an emergency department using a deep neural network approach," Kybernetes, vol. 49, no. 9, pp. 2335-2348, 2019.

[21] P. Aboagye-Sarfo, Q. Mai, F. M. Sanfilippo, D. B. Preen, L. M. Stewart, and D. M. Fatovich, "A comparison of multivariate and univariate time series approaches to modelling and forecasting emergency department demand in western Australia," Journal of Biomedical Informatics, vol. 57, pp. 62-73, 2015.

[22] M. Carvalho-Silva, M. T. T. Monteiro, F. d. Sá-Soares, and S. Dória-Nóbrega, "Assessment of forecasting models for patients arrival at emergency department," Operations Research for Health Care, vol. 18, pp. 112-118, 2018.

[23] T. Jilani, G. Housley, G. Figueredo, P.-S. Tang, J. Hatton, and D. Shaw, "Short and long term predictions of hospital emergency department attendances," International Journal of Medical Informatics, vol. 129, pp. 167-174, 2019.

[24] A. Ekström, M. Nordberg, and O. Eriksson, "Shorter waiting time, better emergency healthcare: forecasting Stockholm's emergency department visits," Model Assisted Statistics and Applications, vol. 13, no. 4, pp. 377-385, 2018.

[25] D. Golmohammadi, "Predicting hospital admissions to reduce emergency department boarding," International Journal of Production Economics, vol. 182, pp. 535-544, 2016.

[26] Y. Zhang, L. Luo, J. Yang, D. Liu, R. Kong, and Y. Feng, “A hybrid ARIMA-SVR approach for forecasting emergency patient flow," Journal of Ambient Intelligence and Humanized Computing, vol. 10, no. 8, pp. 3315-3323, 2019.

[27] Q. Xu, K.-L. Tsui, W. Jiang, and H. Guo, "A hybrid approach for forecasting patient visits in emergency department," Quality and Reliability Engineering International, vol. 32, no. 8, pp. 2751-2759, 2016.

[28] R. Calegari, F. S. Fogliatto, F. R. Lucini, J. Neyeloff, R. S. Kuchenbecker, and B. D. Schaan, "Forecasting daily volume and acuity of patients in the emergency department," Computational and Mathematical Methods in Medicine, vol. 2016, Article ID 3863268, 8 pages, 2016.

[29] I. Marcilio, S. Hajat, and N. Gouveia, "Forecasting daily emergency department visits using calendar variables and ambient temperature readings," Academic Emergency Medicine, vol. 20, no. 8, pp. 769-777, 2013. 
[30] S. A. Jones, M. P. Joy, and J. Pearson, "Forecasting demand of emergency care," Health Care Management Science, vol. 5, no. 4, pp. 297-305, 2002.

[31] S. Tideman, M. Santillana, J. Bickel, and B. Reis, "Internet search query data improve forecasts of daily emergency department volume," Journal of the American Medical Informatics Association, vol. 26, no. 12, pp. 1574-1583, 2019.

[32] D. M. Himmelblau, "Accounts of experiences in the application of artificial neural networks in chemical engineering," Industrial \& Engineering Chemistry Research, vol. 47, no. 16, pp. 5782-5796, 2008.

[33] O. Onat and M. Gul, "Application of artificial neural networks to the prediction of out-of-plane response of infill walls subjected to shake table," Smart Structures and Systems, vol. 21, no. 4, pp. 521-535, 2018.

[34] B. S. Waziri, K. Bala, and S. A. Bustani, "Artificial neural networks in construction engineering and management," International Journal of Architecture, Engineering and Construction, vol. 6, no. 1, pp. 50-60, 2017.

[35] O. I. Abiodun, A. Jantan, A. E. Omolara, K. V. Dada, N. A. Mohamed, and H. Arshad, "State-of-the-art in artificial neural network applications: a survey," Heliyon, vol. 4, no. 11, Article ID e00938, 2018.

[36] U. J. Frey and H. Rusch, "Using artificial neural networks for the analysis of social-ecological systems," Ecology and Society, vol. 18, no. 2, 2013.

[37] N. Shahid, T. Rappon, and W. Berta, "Applications of artificial neural networks in health care organizational decisionmaking: a scoping review," PLoS One, vol. 14, no. 2, Article ID e0212356, 2019.

[38] D. L. Reilly and L. N. Cooper, "An overview of neural networks: early models to real world systems," in How We Learn; How We Remember: Toward an Understanding of Brain and Neural Systems: Selected Papers of Leon N Cooper, pp. 300321, World Scientific, Singapore, 1995.

[39] G. Zhang, B. E. Patuwo, and M. Y. Hu, "Forecasting with artificial neural networks: the state of the art," International Journal of Forecasting, vol. 14, no. 1, pp. 35-62, 1998.

[40] G. B. Kingston, M. F. Lambert, and H. R. Maier, "Bayesian training of artificial neural networks used for water resources modeling," Water Resources Research, vol. 41, no. 12, pp. 1-11, 2005.

[41] L. T. Le, H. Nguyen, J. Dou, and J. Zhou, "A comparative study of PSO-ANN, GA-ANN, ICA-ANN, and ABC-ANN in estimating the heating load of buildings' energy efficiency for smart city planning," Applied Sciences, vol. 9, no. 13, p. 2630, 2019.

[42] A. Kadiyala, D. Kaur, and A. Kumar, "Development of hybrid genetic-algorithm-based neural networks using regression trees for modeling air quality inside a public transportation bus," Journal of the Air \& Waste Management Association, vol. 63, no. 2, pp. 205-218, 2013.

[43] E. Pekel and S. S. Kara, "Passenger flow prediction based on newly adopted algorithms," Applied Artificial Intelligence, vol. 31, no. 1, pp. 64-79, 2017.

[44] E. Pekel and S. Soner Kara, "Solving capacitated location routing problem by variable neighborhood descent and GAartificial neural network hybrid method," Promet-Traffic \& Transportation, vol. 30, no. 5, pp. 563-578, 2018.

[45] R. Eberhart and J. Kennedy, "A new optimizer using particle swarm theory," in Proceedings of the Sixth International Symposium on Micro Machine and Human Science, pp. 39-43, IEEE, Nagoya, Japan, October 1995.
[46] M. Abbaspour Onari, S. Yousefi, and M. Jahangoshai Rezaee, "Risk assessment in discrete production processes considering uncertainty and reliability: $Z$-number multi-stage fuzzy cognitive map with fuzzy learning algorithm," Artificial Intelligence Review, vol. 54, no. 2, pp. 1349-1383, 2021. 